\title{
Hairy kisses: tactile cheliceral courtship affects female mating decisions in Leucauge mariana (Araneae, Tetragnathidae)
}

\section{Anita Aisenberg, Gilbert Barrantes \& William G. Eberhard}

\section{Behavioral Ecology and Sociobiology}

ISSN 0340-5443

Volume 69

Number 2

Behav Ecol Sociobiol (2015) 69:313-323

DOI 10.1007/s00265-014-1844-2

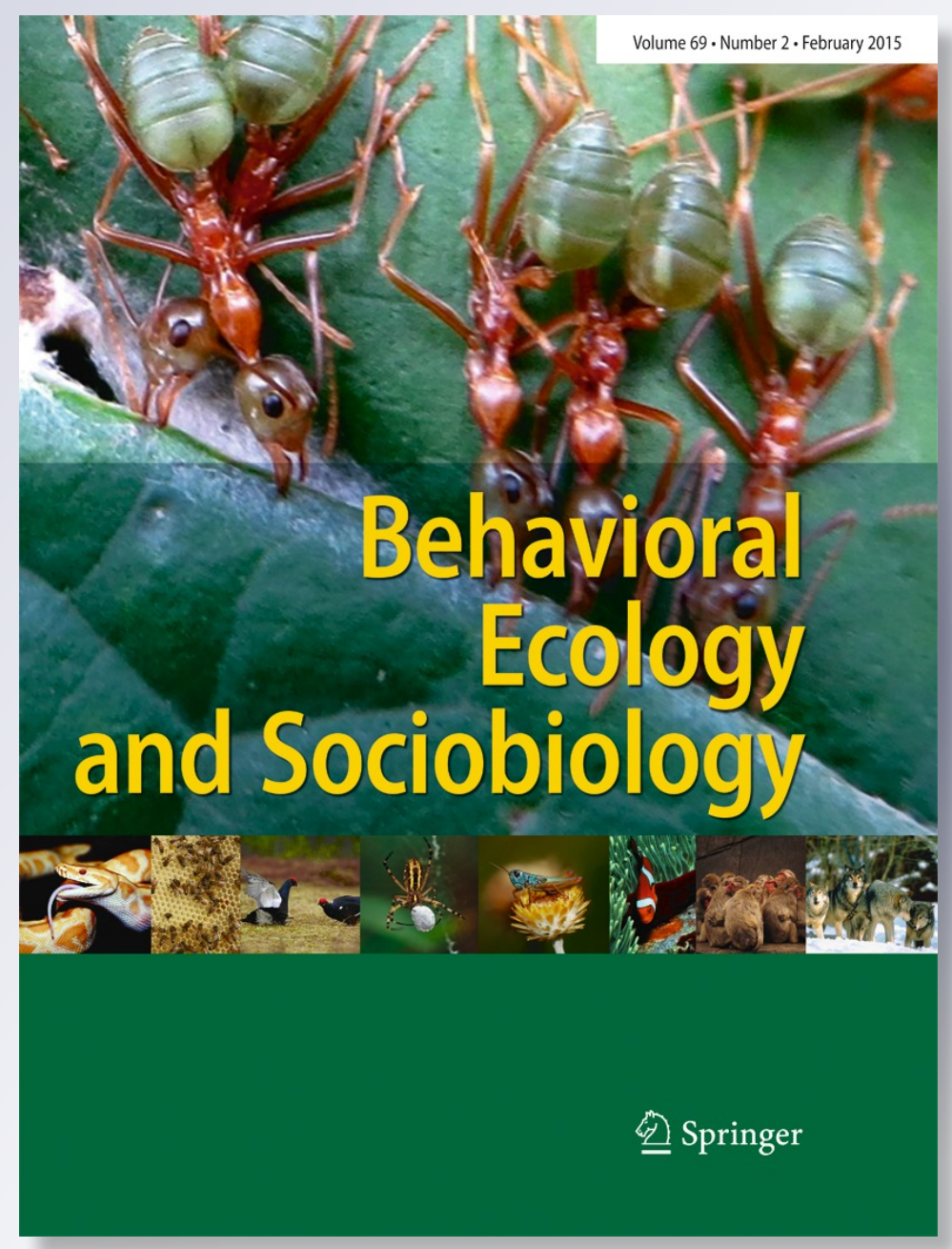

黛 Springer 
Your article is protected by copyright and all rights are held exclusively by SpringerVerlag Berlin Heidelberg. This e-offprint is for personal use only and shall not be selfarchived in electronic repositories. If you wish to self-archive your article, please use the accepted manuscript version for posting on your own website. You may further deposit the accepted manuscript version in any repository, provided it is only made publicly available 12 months after official publication or later and provided acknowledgement is given to the original source of publication and a link is inserted to the published article on Springer's website. The link must be accompanied by the following text: "The final publication is available at link.springer.com". 


\title{
Hairy kisses: tactile cheliceral courtship affects female mating decisions in Leucauge mariana (Araneae, Tetragnathidae)
}

\author{
Anita Aisenberg • Gilbert Barrantes • William G. Eberhard
}

Received: 8 September 2014 / Revised: 27 October 2014 / Accepted: 30 October 2014 / Published online: 14 November 2014

(C) Springer-Verlag Berlin Heidelberg 2014

\begin{abstract}
Sexual selection is thought to be an important force driving the evolution of sexually dimorphic morphology and behavior, but direct experimental tests of the functions of species-specific details of morphology are rare and usually incomplete. The males of most species of the large spider family Tetragnathidae possess large sexually dimorphic chelicerae that are used when the sexes lock together before and during mating. In Leucauge mariana, the female's chelicerae clasp those of the male; mating does not begin until the female's chelicerae seize the male and does not end until they release him. In addition, females contribute material to form genital plugs in the female's genitalia. Male chelicerae have sexually dimorphic and species-specific setae and ledges in areas that contact the female during cheliceral clasps. We tested the hypothesis that stimuli from these structures trigger mating processes that are controlled by the female which could increase male reproductive success. We reduced or eliminated possible stimulation of the female in two ways: removing male cheliceral setae that contact the female, and removing setae on the female's chelicerae and endites that are contacted by and could thus be stimulated by the male's chelicerae and their setae. Both male and female modifications
\end{abstract}

Communicated by D. Gwynne

A. Aisenberg $(\bowtie)$

Laboratorio de Etología, Ecología y Evolución, Instituto de

Investigaciones Biológicas Clemente Estable, Avenida Italia 3318,

CP 11600 Montevideo, Uruguay

e-mail: anita.aisenberg@gmail.com

G. Barrantes • W. G. Eberhard

Escuela de Biología, Universidad de Costa Rica, Ciudad

Universitaria, Costa Rica

W. G. Eberhard

Smithsonian Tropical Research Institute, Department of Biology,

Louisiana State University, Baton Rouge, LA, USA had similar effects that likely reduced the male's chances of paternity: female receptivity to re-mating increased, copulatory plug formation decreased, and interruptions during copulation became more frequent. As expected under the stimulation hypothesis, blocking female sensory abilities generally had greater effects on these responses than modifying male stimulatory structures.

Keywords Sexual selection - Cryptic female choice · Experimental manipulation $\cdot$ Cheliceral clasp $\cdot$ Leucauge

\section{Introduction}

Studies of the male stimulation of females during sexual interactions have mostly concentrated on three female sensory modalities - vision, hearing (and substrate vibrations), and (to a lesser extent) olfaction (Andersson 1994). This bias has had important consequences in the designs of experiments testing whether or not particular male courtship stimuli influence male's paternity. It is often feasible to mimic these types of male signals experimentally, but the complementary experiment, of selectively blocking female sensitivity to particular male stimuli (thus controlling for possible changes in the male's behavior as a result of his being experimentally modified), is generally not possible without seriously incapacitating the female. This asymmetry can result in weaknesses in experimental designs.

Indeed, some widely cited experiments, which have tested female preferences for male signals by altering male stimuli by altering the male himself, such as by lengthening or shortening bird tail feathers (Andersson 1982, 1994; Møller 1994), or fish fins (Basolo 1990), lack controls for the possible effects that these alterations may have had on the male's own subsequent behavior. Furthermore, some studies have shown that 
males may behave differently when his traits are artificially modified (Safran et al. 2008; Rubenstein and Hauber 2008).

Another consequence of the bias toward visual, auditory, and chemical stimuli is that comparative analyses of evolutionary changes in female sensitivity to male signals in different species are also difficult. Do females of widow birds or barn swallows have especially refined central nervous system abilities that respond differentially to the sight of different lengths of male tail feathers? Have such female abilities evolved in concert with changes in the male structures in different species? Experimental modification across taxa of the relevant female sense organs, such as her eyes, would not provide the data to answer such questions, while modifications of particular central processing abilities deep in her CNS would be technically difficult.

These difficult problems for experimental studies of sexual selection can be overcome to some extent in studies of male structures that function to stimulate females in the tactile mode (Eberhard 2011). In some cases, the tactile sense organs in the area of the female's body that are stimulated by the male structure have few other important functions, and their sensitivities can be modified very selectively without affecting other female sensitivities or abilities. In addition, such modifications can test for the effects of stimulation per se, as opposed to other possible physically coercive effects that the male may have on the female (Arnqvist and Rowe 2005). In addition, simple morphological measurements such as the comparative abundance of female tactile sense organs in the area contacted by the male, compared with adjacent areas on the same female (Eberhard 2001) and with those of the male and of the females of related species (Córdoba-Aguilar 1999, 2002, 2005; Ingram et al. 2008), can reveal evolutionary adjustments of females to male stimulation. Documenting such male-female coevolution is particularly important for sexual conflict hypotheses, which predict frequent coevolutionary reduction in female sensitivity to male stimulatory structures that diverge rapidly (e.g., Córdoba-Aguilar 2002).

In sum, the controls that are often missing from classic experimental studies of the stimulatory function of male structures on females can be relatively easily incorporated in studies of male tactile courtship structures. There is a general pattern of rapid divergent evolution for such structures, including male genitalia and other traits that are specialized to contact the female during sexual encounters, throughout the animal kingdom (Eberhard 1985, 1996; Arnqvist and Rowe 2005; Leonard and Córdoba-Aguilar 2010). Post-copulatory sexual selection, including sperm competition, cryptic female choice, and sexually antagonistic coevolution, is thought to be one of the main evolutionary forces responsible for this trend (Eberhard 1985, 2009; Arnqvist and Rowe 2005; Leonard and Córdoba-Aguilar 2010). It is possible to test for possible sexual selection by modifying both the male contact structures and the female's abilities to sense these structures, and then checking for the effects on female responses and on paternity (e.g., Uetz et al. 1996; Córdoba-Aguilar 2002; Briceño and Eberhard 2009a, b; Polak and Rashed 2009). This combination of male and female modifications provides a crucial control for the possibility that experimental modification of the male's morphology also results in changes in his behavior.

Here we examine the possibility of male tactile courtship in a spider, using reciprocal modifications of male and female structures in the orb-weaving tetragnathid Leucauge mariana (Keyserling 1881). The family Tetragnathidae includes approximately 1,000 species in 51 genera (Platnick 2013). Most members of this family have large and conspicuous chelicerae, and the female and male generally clasp each other with their chelicerae before and during mating (Eberhard and Huber 1998; Álvarez-Padilla and Hormiga 2011). It has been argued that cheliceral locking could be a male adaptation that allows the male to anchor himself (and his relatively simple secondary genitalia, his palps) more securely to the female's body during copulation (Levi 1981; Kraus 1984). However, in some tetragnathids, it is the female which seizes male chelicerae rather than vice versa (Eberhard and Huber 1998) and at least one species of Lencauge is able to copulate without locking chelicerae (Aisenberg et al. unpublished data). The courtship and copulation behavior of L. mariana have been described by Eberhard and Huber (1998) and Aisenberg (2009). Males initiate courtship by vibrating the female's web; a receptive female responds by turning toward the male, spreading her anterior legs, opening her cheliceral fangs wide, and bending her abdomen ventrally toward the male. If the female (which is, on average, larger than the male) does not perform any of these receptive responses, the male cannot proceed with mating, and he eventually ceases to court. Thus, physical coercion by the male is impossible in this species; mating can only occur if the female performs overt receptive behavior.

The male and female lock their chelicerae together just prior to and throughout copulation. During the later stages of mating, the male deposits a white substance on the surface of the female's external genitalia (the epigynum) with his palps. This substance, if the female adds additional material from within her insemination ducts, forms a copulatory plug on or near the entrances to the two insemination ducts (Eberhard and Huber 1998; Méndez 2004; Aisenberg and Eberhard 2009; Méndez and Eberhard in press). Thus, both mating acceptance per se and copulatory plug formation are under female control. The degree of female cooperation in both contexts could be affected by male stimulation.

The objective of the present study was to test whether stimulation by the male chelicerae during cheliceral clasps in L. mariana affects female responses in ways that might influence the male's chances of paternity. For this purpose, we shaved male cheliceral setae, and also shaved those setae on the female's chelicerae and endites which are often contacted 
by male's chelicerae; we analyzed the effects of these manipulations on courtship duration, female mating acceptance, mating characteristics, female receptivity to re-mating and re-mating characteristics, and copulatory plug formation after first and second mating. As has been shown for other arthropods and spiders (Eberhard 1996, 2011), including Leucauge (Aisenberg and Eberhard 2009; Aisenberg and Barrantes 2011), variation in male stimulation during mating can affect female decisions regarding male paternity success.

These particular mechanisms are only a subset of the ways in which a female could potentially bias paternity (Eberhard 1996). The particular mechanisms used by a particular species are not predictable, and we would thus be amiss if we were to claim that we can predict them. We can, however, predict the directions in which changes of female responses (if they do occur). We hypothesized that if the sexually dimorphic traits of the male chelicerae have evolved under copulatory or postcopulatory sexual selection to stimulate the female in ways that increase the male's chances of paternity, then any female responses that were affected by these modifications would be biased in predictable ways that would potentially reduce the male's expected paternity. We thus expected that if there were changes in female responses when the male or the female was shaved, the females would open their chelicerae and interrupt mating more frequently, the total duration of matings would be shorter, copulatory plugs would be less frequently formed, and re-mating would be more frequent than in control spiders.

\section{Methods}

\section{Reproductive biology of L. mariana}

During copulation, the male repeatedly inserts his secondary genital organs (his palps) into the two openings of the insemination ducts on the female's rigid external genitalic plate (epigynum) (we will call the entire period, from first palpal insertion to final withdrawal and including any cheliceral contact that preceded or followed palpal insertions, a "copulation"). Relatively long palpal insertions are thought to involve transfer of semen to the female; short insertions are associated with transfer of plug material, which can be seen on the surface of the female's epigynum (Eberhard and Huber 1998). A cheliceral clasp began when the male brought the tips of the basal segments of his chelicerae (with his fangs closed) close to the female's chelicerae; she spread the basal segments of her chelicerae and opened her fangs, then clasped the distal portion of the basal segment of his chelicerae by closing her fangs (this is termed a "cheliceral clasp"). The male chelicerae possess two sexually dimorphic traits (Fig. 1): a cheliceral process (ledge) at the distal lateral corner on the anterior surface of his basal cheliceral segment and setae on the anterior surface of the basal segment that are more

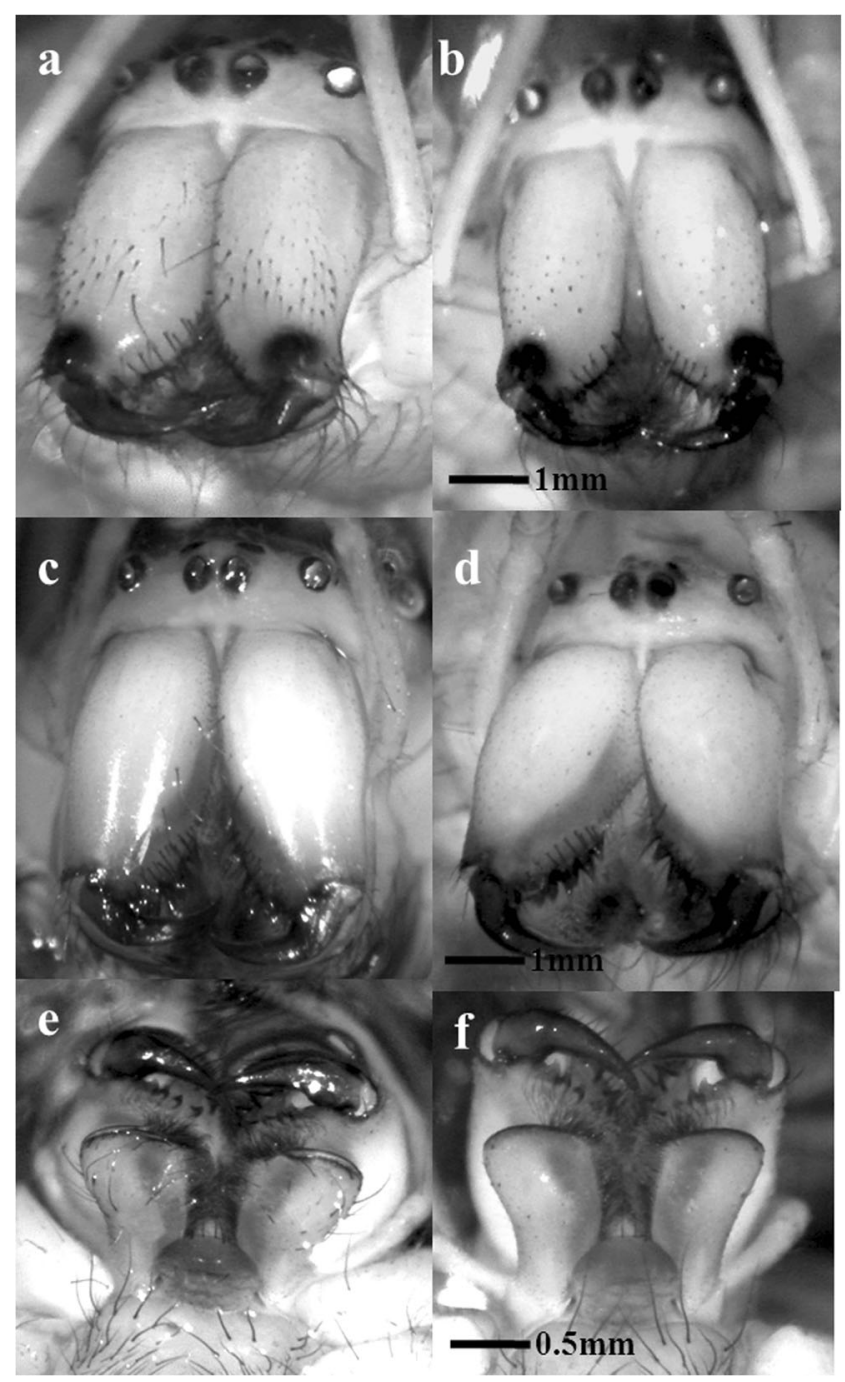

Fig. 1 Anterior views of the unshaved (a) and shaved (b) chelicerae of a male, and the unshaved (c) and shaved (d) chelicerae of a female, and ventral views of the endites of an unshaved (e) and shaved (f) female

abundant than those on the females' chelicerae (Eberhard and Huber 1998). The lateral margin of the basal segment of the male chelicera also projects laterally near the distal tip. Females possess setae on the anterior surface of the basal segment of their chelicerae that are contacted by the anterior surface of the male chelicerae during the clasp (Fig. 1). Spider setae have an innervated membrane at their bases; their neurons respond to deformation of the membrane caused by pressure or movement (Foelix 2011) and are thus tactile sense organs.

Females can interrupt or terminate a copulation in two ways: by pushing the male's palp from her genitalia with a leg or (more often) by opening her fangs to break the cheliceral clasp, which often results in the male withdrawing his palp and separating at least temporarily from the female (Eberhard and Huber 1998; Aisenberg 2009). The differences in male and female cheliceral morphology, the characteristics 
of the cheliceral clasp, and the ability of the female to influence both the initiation and the termination of mating suggest the possibility that the dimorphic male cheliceral structures could be under sexual selection by female choice in this species.

\section{Procedures}

We captured adult males and sub-adult females of L. mariana on the campus of the Universidad de Costa Rica $\left(9^{\circ} 54{ }^{\prime} \mathrm{N}\right.$, $84^{\circ} 03^{\prime} \mathrm{W}$; elevation 1,200 m), San José Province, Costa Rica, from October to December 2011. Virgin females were obtained by collecting penultimate female nymphs that were about to molt to maturity on resting webs, where they were guarded by adult males (Eberhard et al. 1993). We housed the spiders individually in 10.0-cm-high plastic cups that were $7.5 \mathrm{~cm}$ in diameter at the top and $5.5 \mathrm{~cm}$ at the bottom, with a small branch as a support and a small wad of wet cotton. We checked females four times a day to determine when they molted.

In order to test for the possibility of sexual selection on other traits which are morphologically associated with the male cheliceral setae, we checked for sexual dimorphisms by measuring carapace width to estimate body size (Eberhard et al. 1998; Moya-Laraño and Cabeza 2003; Foellmer and Fairbarin 2005), the length of the left basal cheliceral segment seen in lateral view, and the length and width of the left endite in ventral view in both males and females. The improved understanding that resulted from our observations of the positions and movements of the male chelicerae during copulation led us to appreciate an additional female trait, the long setae on the anterior margin of the female's sternum. These setae may also play an important role in enabling the female to sense male stimulation, so we also checked for sexual dimorphism by measuring these setae. We first plucked three of the longest four setae in ten females and ten males of specimens that had been preserved in $70 \%$ ethyl alcohol, using a hooked minuten pin. Seta I was the one closest to the mouth parts in that row (Figs. 2 and 3). We photographed each seta under a light microscope and then measured it using the program Image Tool 2.0. We preserved all spiders in $70 \%$ ethyl alcohol and deposited voucher specimens in the Museo de Zoología, Escuela de Biología, Universidad de Costa Rica.

To test the possibility that tactile stimulation of the female by the male cheliceral setae affects female mating and plug formation, we created three experimental groups: a shaved male mated with a normal virgin female $(n=21)$; a normal male mated with a shaved virgin female $(n=20)$; and a control group, in which a normal male mated with a normal female $(n=20)$. We shaved males by clamping them gently between blocks of soft foam rubber, and then scraping off the setae on the basal cheliceral segments with a fragment of a razor blade

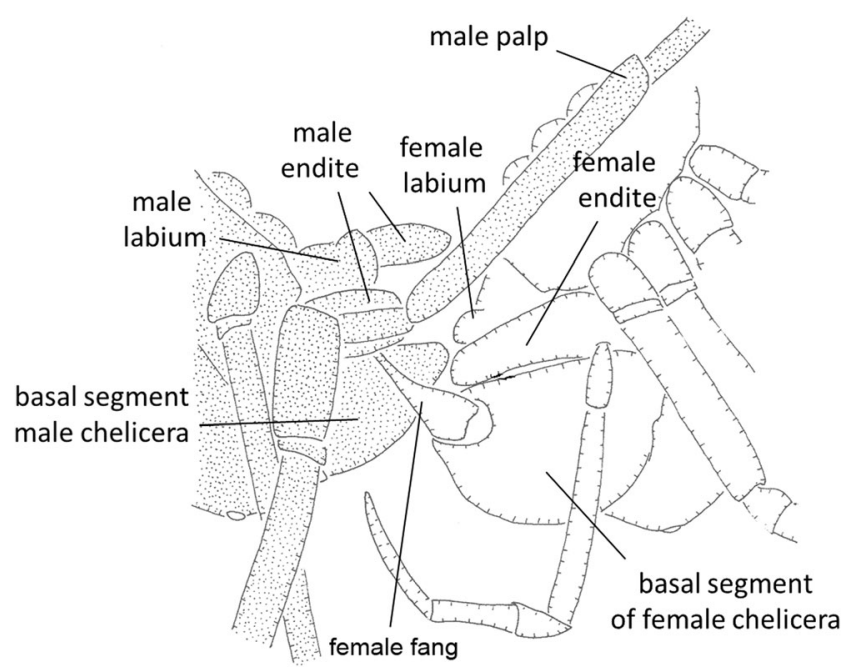

Fig. 2 Positions of clasped male (stippled) and female during mating. The female's fang embraces the distal portion of the basal segment of the male's chelicera (the male's fang is not visible from this angle). The sexually dimorphic setae on the anterior surface of the male chelicerae contact the anterior surface of the female's chelicerae; the distal portion of the basal segment of the male's chelicerae contact the female's endite

under a dissecting microscope (Fig. 1). We shaved females in a similar way, and cut the setae along the anterior surface of the basal segment of each chelicera and on the ventral surfaces of both endites (Fig. 1). We did not observe hemolymph loss or any other sign of injury (e.g., increased rate of grooming of the shaved area) in shaved females or males. We manipulated normal males and females in the control group as if to shave them but did not remove any setae (they were placed in the foam rubber for a similar period, then released). We waited at least $24 \mathrm{~h}$ after manipulation before the behavioral trials to reduce the effects of stress. All the shaved males courted and mated when they encountered females, and courtship duration did not show differences among the groups. Similarly, shaved females all responded to male courtship by adopting the receptive posture, opening their chelicerae and accepting mating.

We placed each virgin female $1-5$ days after she had molted to maturity on a field-collected orb web of a mature female L. mariana. As in previous studies of sexual behavior of Leucauge (e.g., Aisenberg 2009; Aisenberg and Eberhard 2009; Méndez and Eberhard in press), we attached the web to a plastic plate $22 \mathrm{~cm}$ in diameter and about $2 \mathrm{~cm}$ deep, and then added an adult male collected from the field on the same day of the trial (Aisenberg 2009; Aisenberg and Eberhard 2009). All spiders mated in their first pairing. Immediately after mating ended, and then approximately $24 \mathrm{~h}$ later, each female was observed and photographed under a dissecting microscope as she rested on a web to check for the presence of a copulatory plug on her epigynum. Twenty-four hours after her first mating, each female was exposed to a second male with the same characteristics as her first male (shaved or 
Fig. 3 Movements of the fangs of the male (stippled) during copulation. When fully extended (solid lines), the male's fang occasionally deflected one or more the female's sternal setae. More often, less complete extensions (dotted lines) deflected setae on her endites a

b

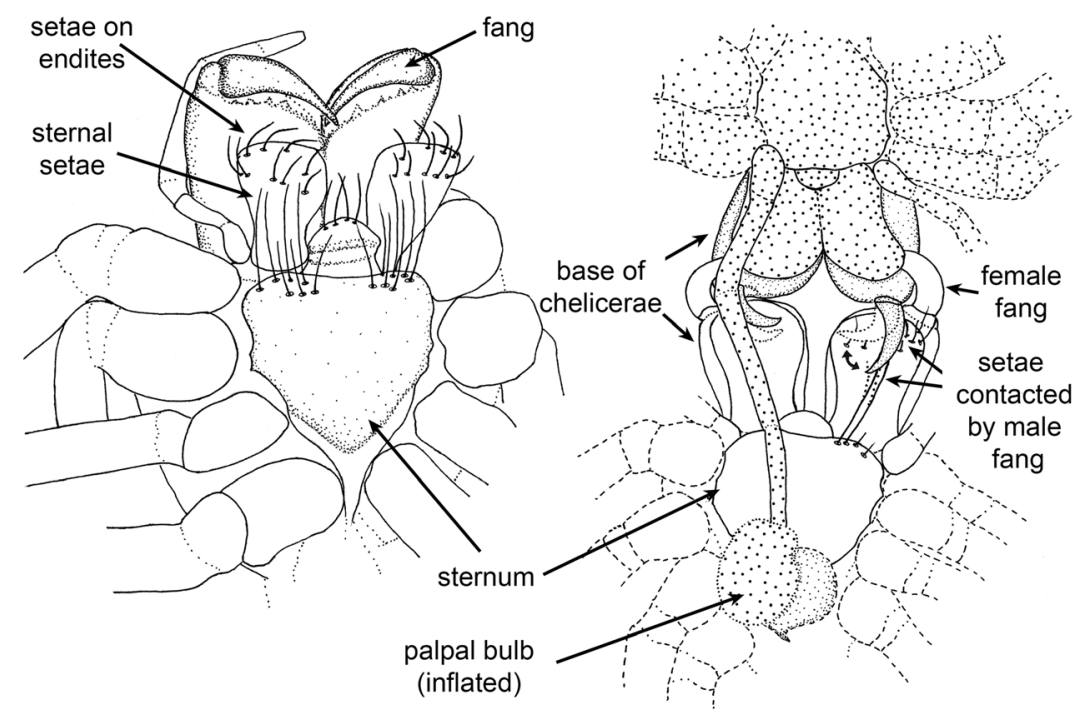

unshaved) (thus mirroring the situation for shaved females, in which the female was shaved for both her first and second encounters with a male). We made video recordings of all first matings of females with a Dino-Eye Eyepiece digital color camera (Model AM423X) attached to the ocular of a Wild Model M3Z dissecting microscope (Wild Company, New York, USA); we also took still photos with the same setup. In first and second matings, we recorded courtship duration, whether copulation occurred and how long it lasted; we checked whether a plug was present immediately after copulation and $20 \mathrm{~h}$ later. No male was used for more than one pairing.

We counted the numbers of opening and closing movements of the male's fangs during cheliceral clamps in video recordings of first matings. Often the tibia of the pedipalp being inserted into the female genitalia hid one male fang, so we counted the movements of the fang opposite to this palp. Fangs sometimes went out of focus when the spiders shifted positions, and we only counted fang movements when we had a clear view of the fangs. The basal segments of the male's chelicerae also moved during cheliceral clasps, but we were unable to see them well enough to make detailed descriptions.

We analyzed courtship and copulatory behavioral using J Watcher software (Blumstein et al. 2000). The duration of pre-copulatory courtship was taken to be from the moment when the male first performed courtship behavior on the web (flexion of his anterior legs strongly and quickly without releasing the silk line that connects him with the female, rock his body by flexing and extending legs IV rhythmically, vibrate his abdomen, rubbing his palps rapidly against each other, strum the web with legs III, tap the female on her legs and/or dorsum) (Eberhard and Huber 1998; Aisenberg and Eberhard 2009), until when the cheliceral clasp began. We measured female cooperation during copulation as the total number of cheliceral disengagements; all copulations had one disengagement at the end, but some were interrupted by one or more additional, temporary disengagements. Palpal insertions were classified as "short" when they included only one hematodochal inflation and "long" when they included multiple inflations (Eberhard and Huber 1998) (the hematodochae are inflatable membranes that expand hydraulically and cause palpal sclerites to move-Eberhard and Huber 1998; Foelix 2011). During mating, males performed leg-pushing behavior that consisted of rhythmic extension of legs I and II against the corresponding female anterior legs (Eberhard and Huber 1998; Aisenberg 2009).

Table 1 Response and explanatory variables included in the analyses

\begin{tabular}{ll}
\hline Variable & Type of variable \\
\hline Treatment & Explanatory \\
Plug formed right after copulation & Response \\
Plug formed at $24 \mathrm{~h}$ & Response \\
Recopulation & Response \\
Total duration of short insertions/number & Explanatory \\
$\quad$ of short insertions & Explanatory \\
Total duration of long insertions/number & \\
of short insertions & Explanatory \\
Number of chelicerae disengagements & Explanatory \\
Number of sequences of leg pushes & Explanatory \\
Courtship duration & Response/explanatory \\
Copulation duration &
\end{tabular}


a

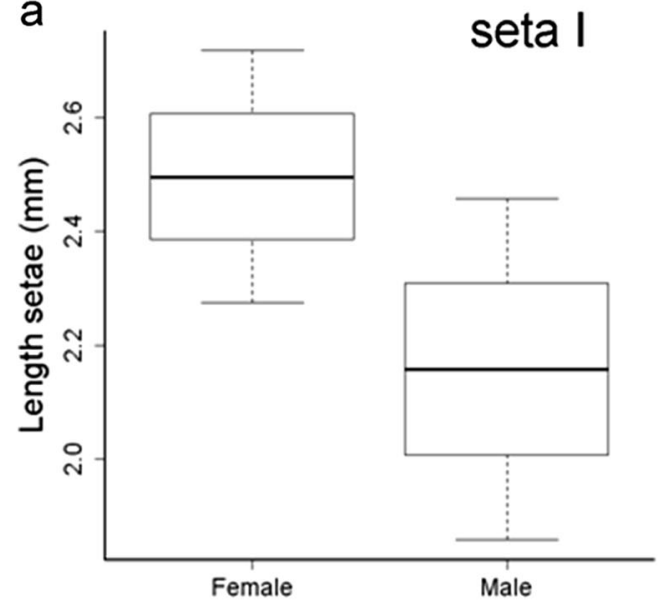

b

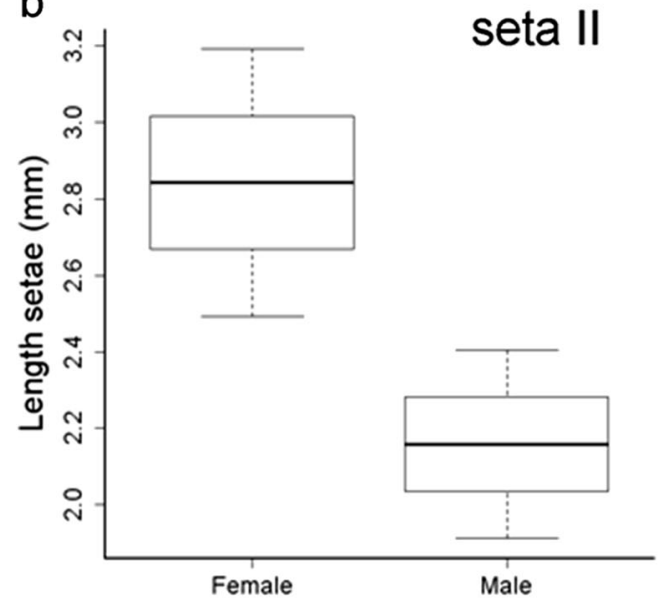

C

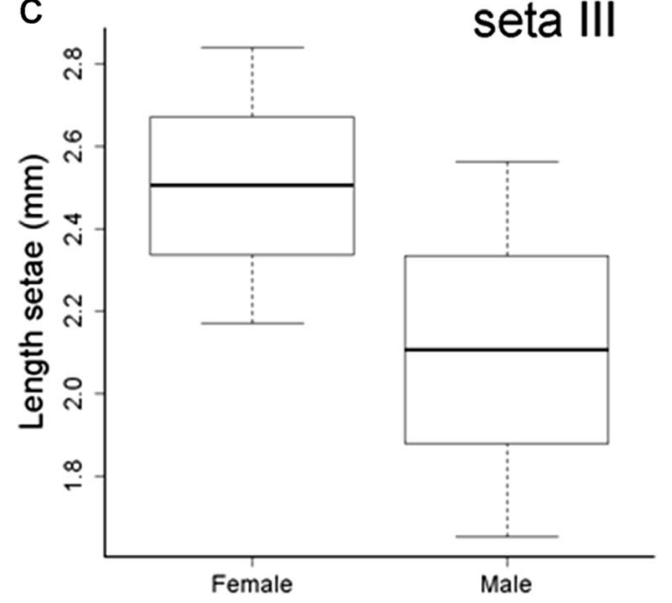

Fig. 4 Length (mean, SD, and 2-SD) of the three longest setae from the anterior margin of female sternum

Statistical analyses

We analyzed binomial response variables (e.g., presence/ absence of copulatory plug) using Generalized Linear Models (GLM) with a binomial probability distribution: $y_{i} \sim$ $x_{1}+x_{2}+\ldots x_{n}$, family=binomial. For continual response variables (e.g., cop), we also used GLMs but with a normal probability distribution. For each response variable, we selected a set of possible models and then choose the optimal model using the Akaike information criteria (Zuur et al. 2009). To construct the models, we included only those explanatory variables whose time of execution made it feasible for them to affect the response variable (Table 1). For instance, to construct the set of models designed to test the effect of explanatory variables on "copulation duration", we included only those behavioral explanatory variables that occurred prior or during copulation. We used the R statistical language, version 3.0.1 (R Development Core Team 2013) for these analyses.

\section{Results}

There was no sexual dimorphism in chelicera length, endite length, or endite width. Female cephalothorax width was greater than that of males $\left(U=351, N_{1}=62, N_{2}=63, P=\right.$ 0.0001 with Mann-Whitney $U$ test), and larger individuals of both sexes had longer chelicerae $\left(R=0.26, F_{1,60}=4.32, P=\right.$ 0.04 for females; $R=0.34, F_{1,61}=8.2, P=0.006$ in males). Correcting for body size, however, the sexes did not differ in cheliceral length ( $\left.U=1,657, N_{1}=62, N_{2}=63, P=0.14\right)$, endite length $\left(U=1,860, N_{1}=62, N_{2}=63, P=0.64\right)$, or endite width $\left(U=1,860, N_{1}=62, N_{2}=63, P=0.65\right)$.

Photos taken from several angles revealed that the areas with abundant setae on the anterior surface of the male's chelicerae contacted the female's chelicerae and endites

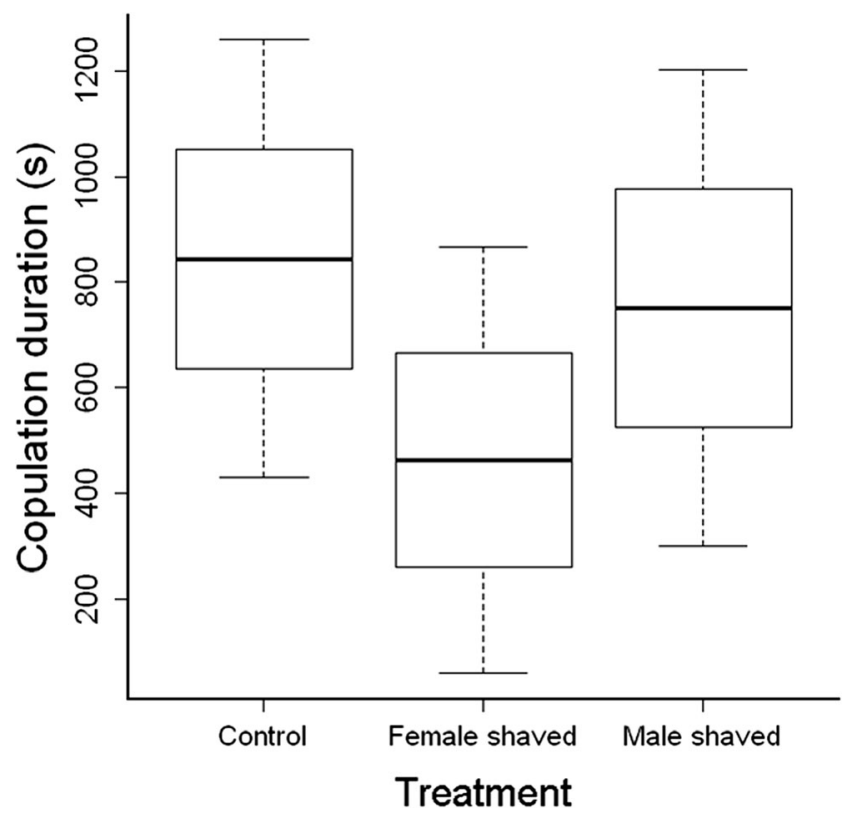

Fig. 5 Effect of treatment (Control, Female shaved, and Male shaved) on copulation duration (mean, SD, and 2-SD) 
Table 2 Effect of group treatments and courtship duration on duration of copulation (optimal GLM)

\begin{tabular}{lllll}
\hline Effect & Coefficient & SE & $T$ & $P$ \\
\hline Intercept & 843.98 & 97.68 & 8.64 & $<0.0001$ \\
Shaved females & -381.60 & 140.05 & -2.72 & 0.0086 \\
Shaved males & -93.42 & 134.82 & -0.69 & 0.4913 \\
\hline
\end{tabular}

during cheliceral clasps (Fig. 2). These setae pressed against the distal and median anterior surfaces of the basal segment of the female's chelicerae. The movements of the male's basal segments, which as noted above we were not able to study in detail, may have caused his dimorphic setae to scrape across the female's chelicerae. The ledgelike process near the distal tip of the male's basal cheliceral segment was near to or in contact with the distal edges of the female's endite (the ledge did not contact the female's cheliceral tooth, as suggested by Eberhard and Huber 1998). The female grasped the male's chelicerae with her fangs, which pressed on the distal posterior surfaces of the basal segments of the male's chelicerae.

The male's fangs played no mechanical role in the cheliceral clasp. They opened and closed most of the time during cheliceral clamps (Fig. 3); their movements were either alternate $(80 \%)$ (the mean in six control copulations) or simultaneous. The amplitude of their movements varied from short back-and-forth movements to wide extensions (Fig. 3). Short movements of the male's fangs often deflected setae on the ventral surface of the female's endite, and wide extensions occasionally deflected the long, anteriorly directed setae on the anterior margin of her sternum. The lengths of all three longest setae on the sternum were greater in females than in males (Fig. 4; Generalized Linear Model seta I$F_{1,18}=7.55, P=0.013$; seta $\mathrm{II}-F_{1,18}=18.93, P=0.0004$; seta III $\left.-F_{1,19}=3.77, P=0.067\right)$. The size of the spider (cephalothorax width) had no relation to setae length. Thus, these setae are sexually dimorphic, being relatively longer in females.
A

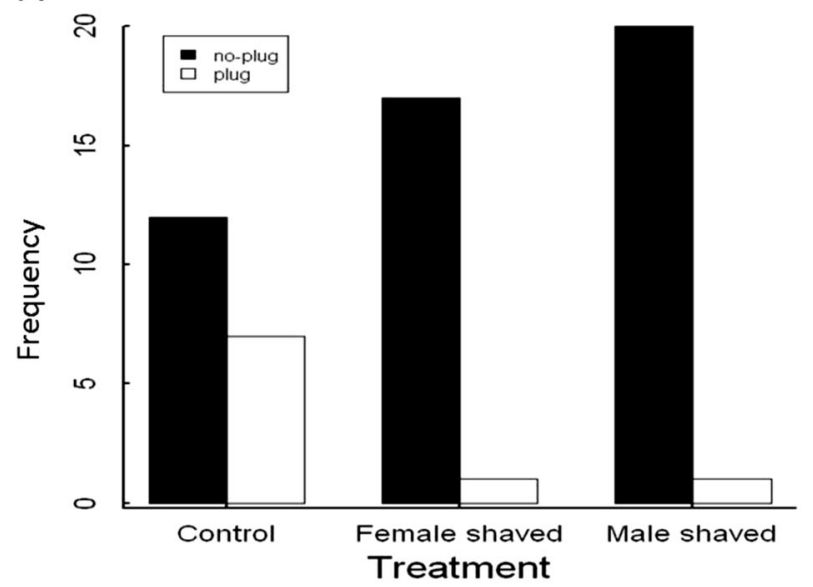

C

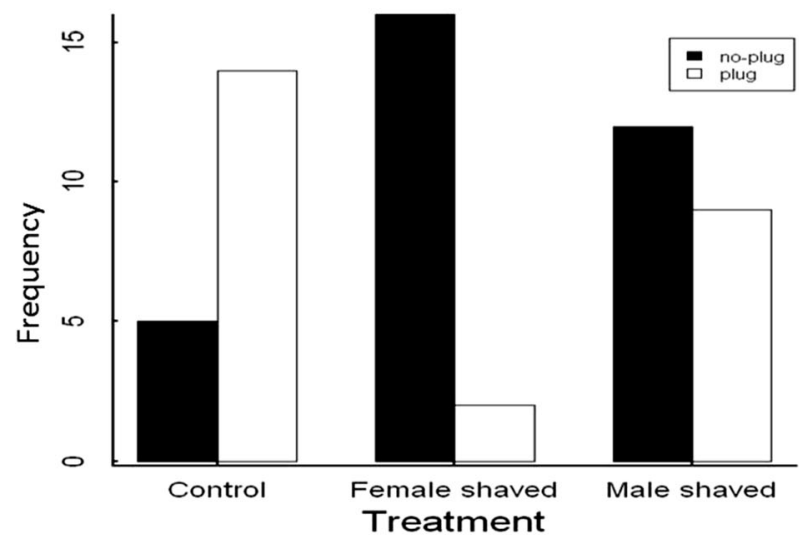

B

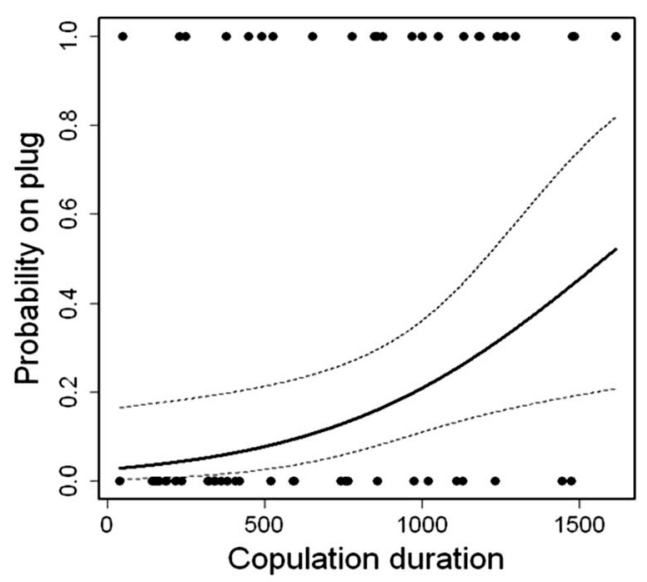

D

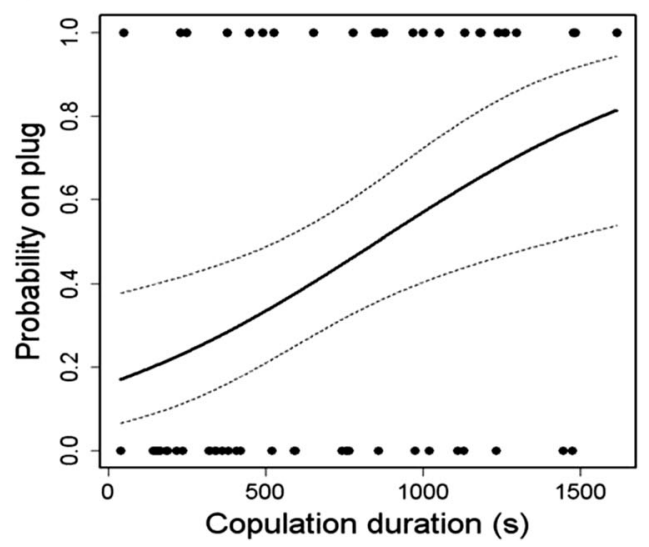

Fig. 6 Mating plugs. a The numbers of pairs in each group in which a plug did or did not form immediately after mating; $\mathbf{b}$ the probability of plug formation immediately after mating versus copulation duration; $\mathbf{c}$ the numbers of pairs in which a plug formed or did not form $24 \mathrm{~h}$ after mating; $\mathbf{d}$ the probability of plug formation $24 \mathrm{~h}$ after mating versus copulation duration 
Table 3 Effect of group treatments, copulation duration, proportion of long and short insertions, and chelicerae disengagement on the formation of copulatory plug right after copulation and $24 \mathrm{~h}$ after copulation (optimal GLM)

\begin{tabular}{lllll}
\hline Effect & Coefficient & SE & $Z$ & $P$ \\
\hline & \multicolumn{4}{l}{ Copulatory plug formed right after copulation } \\
Intercept & -2.57 & 1.14 & -2.26 & 0.0238 \\
Shaved females & -1.75 & 1.21 & -1.45 & 0.1466 \\
Shaved males & -2.55 & 1.18 & -2.17 & 0.0303 \\
Copulation & 0.002 & 0.001 & 2.11 & 0.0344 \\
& Copulatory plug formed & 24 & h after copulation \\
Intercept & -0.54 & 1.12 & -0.48 & 0.6262 \\
Shaved females & -3.51 & 1.19 & -2.95 & 0.0032 \\
Shaved males & -1.48 & 0.82 & -1.79 & 0.0737 \\
Short insertions & -0.57 & 0.41 & -1.39 & 0.1636 \\
Long insertions & -0.01 & 0.00 & -1.60 & 0.1103 \\
Disengagement & 0.79 & 0.42 & 1.87 & 0.0615 \\
Leg pushing & 0.12 & 0.08 & 1.50 & 0.1323 \\
Copulation & 0.002 & 0.001 & 2.52 & 0.0118 \\
\hline
\end{tabular}

\section{Copulation duration}

Duration of copulation was shorter for pairs with shaved females than for control pairs (Fig. 5; Table 2). The duration of pairs with shaved males did not differ significantly from that of control pairs (Table 2). We included two explanatory variables (treatment and courtship duration), but the optimal model included only the treatment as the explanatory variable.

\section{Plug formation}

The formation of copulatory plugs immediately after copulation was relatively less frequent in pairs with shaved males than in control pairs (Fig. 6a; Table 3). The proportion of plugs formed in pairs with shaved females did not differ from the proportion in control pairs (Table 3 ). The probability of plug
Table 4 Effect of group treatments on frequency of chelicerae disengagement (optimal GLM)

\begin{tabular}{lllll}
\hline Effect & Coefficient & SE & $T$ & $P$ \\
\hline Intercept & 1.36 & 0.22 & 6.30 & $<0.0001$ \\
Shaved females & 0.85 & 0.31 & 2.74 & 0.0082 \\
Shaved males & 0.39 & 0.30 & 1.31 & 0.1949 \\
\hline
\end{tabular}

formation increased with the duration of the copulation (Fig. 6b). The optimal model included treatment and copulation duration as explanatory variables, with both having a significant effect.

Formation of copulatory plugs $24 \mathrm{~h}$ after copulation was relatively less frequent in pairs with shaved females than in control pairs (Fig. 6c; Table 3). The proportion of plugs formed in pairs with shaved males did not differ from that in control pairs. The probability of plug formation increased with the duration of the copulation (Fig. 6d; Table 3). The optimal model included treatment, duration of short insertions/number of short insertions, duration of long insertions/number of long insertions, cheliceral disengagements, number of sequences of leg pushes, and copulation duration as explanatory variables, but only treatment and copulation duration had a significant effect on the probability of plug formation.

\section{Cheliceral disengagements}

When the variable cheliceral disengagement was used as one of the predictor variables of plug formation after $24 \mathrm{~h}$, it was included in the group of predictor variables in the optimal models, but with a marginally significant probability. In models of copulation interruption, there was no difference when pairs with shaved male and shaved females were compared with the control pairs. However, the probability of copulation interruption increased significantly with the number of cheliceral disengagements $(Z=3.12, P=0.00181$, Fig. $7 \mathrm{a})$.

We obtained two models with the same maximum optimality in analyses in which disengagement was the response
Fig. 7 Cheliceral

disengagements. a The probability of copulation interruption increased significantly with the number of cheliceral disengagements; $\mathbf{b}$ pairs with shaved females had a significant higher frequency of cheliceral disengagements relative to control pairs ( $t=2.74$, $P=0.0082$ ); pairs with shaved males did not differ from control pairs $(t=1.31, P=0.1949)$
A
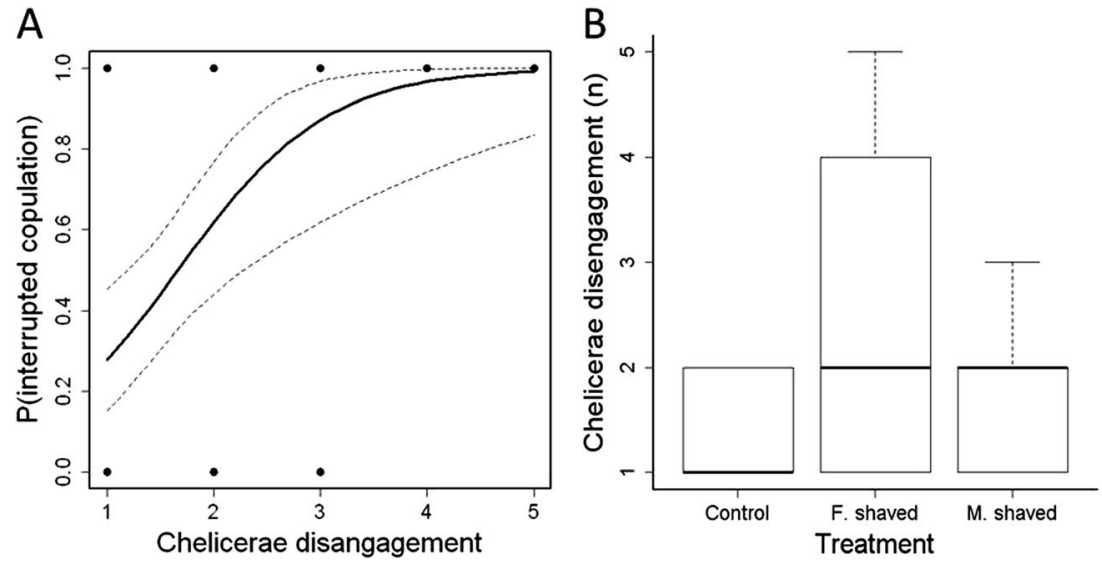
Fig. 8 The numbers of pairs in which the female did and did not re-mate, comparing females with and without a plug

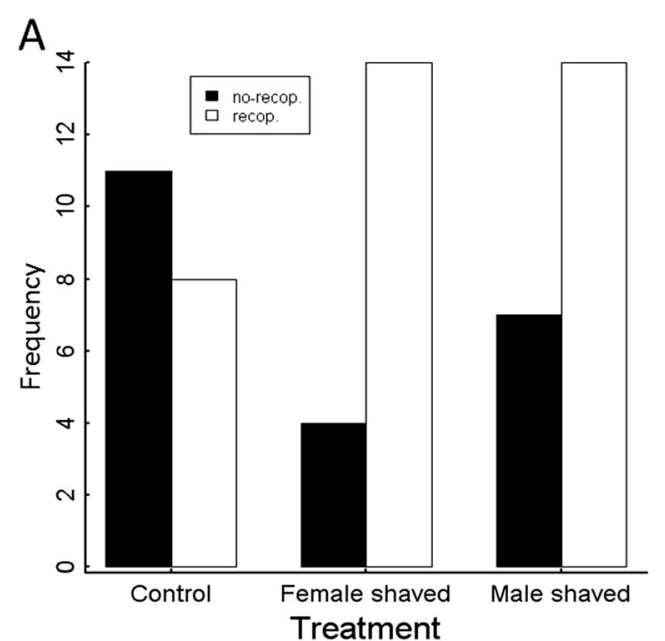

variable: one included copulation duration and treatment as significant predictor variables; the other included only treatment as predictor variable (Table 4). The frequency of chelicerae disengagement was significantly higher in those pairs in which females had been shaved relative to control pairs (Fig. 7b).

\section{Re-mating}

The frequency of re-mating was higher in both pairs with shaved females and with shaved males when compared with control pairs (Fig. 8a; Table 5). The re-matings occurred with higher frequency in those pairs that had not formed a copulatory plug immediately following copulation (Fig. 8b; Table 5). The optimal model included treatment, copulation duration, and formation of the copulatory plug immediately after copulation.

\section{Discussion}

The overall pattern was that experimental reductions of male stimulation of the female with his chelicerae resulted in changes that seem likely to reduce the male's chances of paternity, as

Table 5 Effect of group treatments and courtship duration on duration of copulation (optimal GLM)

\begin{tabular}{lllll}
\hline Effect & Coefficient & SE & $Z$ & $P$ \\
\hline Intercept & -0.28 & 0.82 & -0.34 & 0.7328 \\
Shaved females & 2.11 & 0.89 & 2.37 & 0.0180 \\
Shaved males & 1.93 & 0.84 & 2.30 & 0.0215 \\
Plug formation & 2.73 & 1.13 & 2.41 & 0.0158 \\
Copulation & -0.001 & 0.001 & -1.71 & 0.0872 \\
\hline
\end{tabular}

B

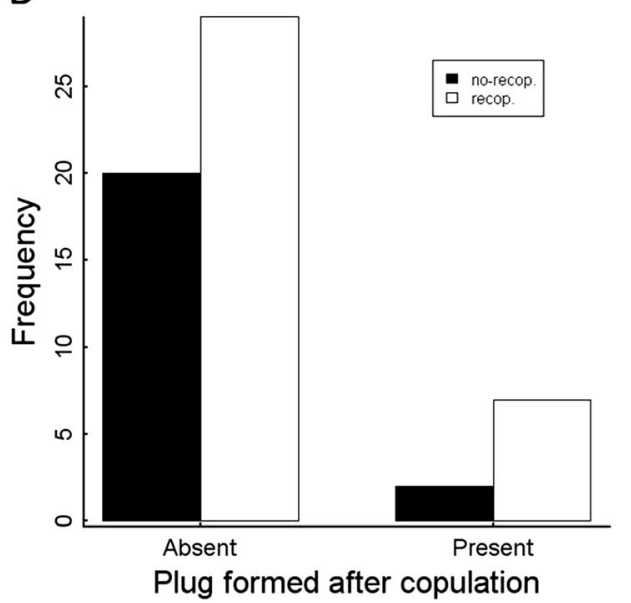

we had hypothesized: plug formation $24 \mathrm{~h}$ after mating was less frequent in shaved females, and female receptivity to remating was greater after matings with shaved males or shaved females. These responses involve processes that in this species are under direct control of the female (Aisenberg and Eberhard 2009); if they affect male paternity (as seems likely, though not certain - see below), they could constitute mechanisms of post-copulatory sexual selection that favor male abilities to stimulate the female.

Another result of female and male modifications was an increase in the frequency of cheliceral disengagements that were unusually short or involved cheliceral clasps that ended before any palpal insertion. These represent female rather than male-initiated interruptions because it is the female which either seizes or fails to seize the male, not vice versa. The increases in these interruptions that occurred when the female was modified could thus represent an additional femaleimposed "impediment" to copulation. There are two likely types of sexual selection that could favor such female selective mechanisms: cryptic female choice (Eberhard 1996) and sexually antagonistic coevolution (SAC) (Arnqvist and Rowe 2005). Of the two, cryptic choice seems at first glance more likely, on the basis of the lack of clearly coevolved female defensive structures or behavior predicted by SAC that would defend against being stimulated by the male. Female defenses could be mediated by her nervous system and thus be invisible. Direct discrimination between these hypotheses could be obtained by determining the relative magnitudes of the costs and benefits to a female of cooperating and not cooperating with a male under natural conditions (Arnqvist and Rowe 2005; Eberhard 2009), but this is far beyond the limits of currently available data in this species (or in any other for that matter-Eberhard 2009). Experimental modifications of females generally resulted in greater effects than modifications of males (Tables 1 and 2). This asymmetry resembles the results of similar experiments on stimulation by male genitalia in tsetse flies (Briceño and Eberhard 2009a, b) and by species- 
specific male front leg clamping organs in sepsid flies (Eberhard 2001, 2002), in which there was also a larger effect when the female sensory structures were masked than when male stimulatory structures were modified. This pattern of a larger effect from modifying females than from modifying males is not surprising. Disabling the female's sensory system would represent a more radical change than a modification of the male structures, which could result in the female still sensing some stimuli, though not exactly the same stimuli that are normally associated with mating. An additional possible explanation of the greater responses to experimental manipulation of females in L. mariana is that our manipulations of males altered only stimuli from the setae on the basal segments of his chelicerae but not those from the movements of his cheliceral fangs; in contrast, our modifications of the female presumably altered her ability to sense both types of stimuli.

Males moved both the basal segments of their chelicerae and their fangs during copulation in ways that seem certain to stimulate the female. Male fang movements deflected female setae on the ventral surfaces of her endites and the long setae on the anterior margin of her sternum. The movements of the basal segments of the male chelicerae, which we were not able to observe in detail, probably also cause deflection of setae on the anterior surface of the basal segment of the female's chelicerae. The frequency of male fang movement did not differ between control and experimental treatments. Thus, the effects of experimental modification of the male were probably due to changes in stimuli resulting from his altered morphology, rather than to behavioral changes. Our experimental masking of the female sense organs did not include her sexually dimorphic, elongate sternal setae. Further experiments will be needed to test the interesting hypotheses that these setae serve to sense male fang movements and that these male movements function as courtship.

There are several limitations in this study. Our tests of receptivity to re-mating were limited to a single context (male and female placed on the same web $24 \mathrm{~h}$ following mating), and some tests applied only to matings of virgin females but not non-virgins. Data on the frequency and timing of male visits to and copulations with females in the field will be needed to determine the biological realism of these experimental protocols. Mating plugs in L. mariana are only partially effective in preventing subsequent insemination attempts by other males, and at least part of this variation is due to differences in the composition of the plugs (Méndez 2004; Méndez and Eberhard in press); we did not measure the composition of plugs that we observed or their abilities to exclude future males. Further studies are also needed to test sperm precedence patterns, which are not known in this species. In another tetragnathid genus, Tetragnatha, both first and second males sometimes obtain paternity (Danielson-François and Bukowski 2005), but their genitalia (especially those of the female) differ from those in L. mariana. Even though there is much yet to learn, we can conclude that at least two female behaviors potentially related with male paternity success, production of mating plugs and re-mating acceptance, are linked to stimulation provided by male cheliceral setae, creating conditions under which cryptic female choice based in cheliceral stimulation received during mating could operate in this spider.

Acknowledgments We thank the Sistema Nacional de Investigadores (Agencia Nacional de Investigación e Innovación) and Programa de Desarrollo de las Ciencias Básicas (AA), the Vicerrectoría de Investigación of the Universidad de Costa Rica (GB, WGE), and the Smithsonian Tropical Research Institute (WGE) for financial support. The editor and two anonymous reviewers improved the final version of the manuscript.

\section{References}

Aisenberg A (2009) Male performance and body size affect female remating occurrence in the orb-web spider Leucauge mariana (Araneae, Tetragnathidae). Ethology 115:1127-1136

Aisenberg A, Barrantes G (2011) Sexual behavior, cannibalism and mating plugs as sticky traps in the orb weaver spider Leucauge argyra (Tetragnathidae). Naturwissenschaften 98:605-613

Aisenberg A, Eberhard WG (2009) Female cooperation in plug formation in a spider: effects of male copulatory courtship. Behav Ecol 20(6): 1236-1241

Álvarez-Padilla F, Hormiga G (2011) Morphological and phylogenetic atlas of the orb-weaving spider family Tetragnathidae (Araneae: Araneoidea). Zool J Linnean Soc 162:713-879

Andersson M (1982) Female choice selects for extreme tail length in a widowbird. Nature 299:818-820

Andersson M (1994) Sexual selection. Princeton University Press, Princeton

Arnqvist G, Rowe L (2005) Sexual conflict. Princeton University Press, Princeton

Basolo A (1990) Female preference predates the evolution of the sword in swordtail fish. Science 250:808-810

Blumstein DT, Evans CS, Daniel JC (2000) JWatcher. Available from: http://galliform.psy.mq.edu.au/jwatcher/

Briceño RD, Eberhard WG (2009a) Experimental modifications imply a stimulatory function for male tsetse fly genitalia, supporting cryptic female choice theory. J Evol Biol 22:1516-1525

Briceño RD, Eberhard WG (2009b) Experimental demonstration of possible cryptic female choice on male tsetse fly genitalia. J Insect Physiol 55:989-996

Córdoba-Aguilar A (1999) Male copulatory sensory stimulation induces female ejection of rival sperm in a damselfly. Proc R Soc Lond B 266:779-784

Córdoba-Aguilar A (2002) Sensory trap as the mechanism of sexual selection in a damselfly genitalic trait (Insecta: Calopterygidae). Am Nat 160:594-601

Córdoba-Aguilar A (2005) Possible coevolution of male and female genital form and function in a calopterygid damselfly. J Evol Biol 18:132-137

Danielson-François AM, Bukowski TC (2005) Female mating history influences copulation behavior but not sperm release in the orbweaving spider Tetragnatha versicolor (Araneae, Tetragnathidae). $\mathrm{J}$ Insect Behav 18:131-148 
Eberhard WG (1985) Animal genitalia and evolution. Harvard University Press, Cambridge

Eberhard WG (1996) Female control: sexual selection by cryptic female choice. Princeton University Press, Princeton

Eberhard WG (2001) The functional morphology of species-specific clasping structures on the front legs of male Archisepsis and Palaeosepsis flies (Diptera, Sepsidae). Zool J Linnean Soc 133: $335-368$

Eberhard WG (2002) Physical restraint or stimulation? The function(s) of the modified front legs of male Archisepsis diversiformis (Diptera, Sepsidae). J Insect Behav 15:831-850

Eberhard WG (2009) Postcopulatory sexual selection: Darwin's omission and its consequences. Proc Nat Sci 106(Suppl 1):10025-10032

Eberhard WG (2011) Experiments with genitalia: a commentary. Trends Ecol Evol 26(1):17-21

Eberhard WG, Huber BA (1998) Courtship, copulation and sperm transfer in Leucauge mariana (Araneae, Tetragnathidae) with implications for higher classification. J Arachnol 26:342-368

Eberhard WG, Guzmán-Gómez S, Catley KM (1993) Correlation between spermathecal morphology and mating systems in spiders. Biol J Linn Soc 50(3):197-209

Eberhard WG, Huber BA, Rodríguez SRL, Briceño RD, Salas I, Rodriguez V (1998) One size fits all? Relationships between the size and degree of variation in genitalia and other body parts in twenty species of insects and spiders. Evolution 52(2):415-431

Foelix RF (2011) Biology of spiders. Oxford University Press, New York

Foellmer MW, Fairbarin DJ (2005) Competing dwarf males: sexual selection in an orb-weaving spider. J Evol Biol 18:629-641

Ingram KK, Laamanen T, Puniamoorthy N, Meier R (2008) Lack of morphological coevolution between male forelegs and female wings in Themira (Sepsidae: Diptera: Insecta). Biol J Linn Soc 93:227-238

Kraus O (1984) Male spider genitalia: evolutionary changes in structure and function. Verh Naturwiss Ver Hamburg 27:373-382

Leonard J, Córdoba-Aguilar A (2010) The evolution of primary sexual characters in animals. Oxford University Press, Oxford
Levi HW (1981) The American orb-weaver genera Dolichognatha and Tetragnatha North of Mexico (Araneae: Araneidae, Tetragnathinae). Bull Mus Comp Zool 149:271-318

Méndez V (2004) Comportamiento sexual y dinámica de población en Leucauge mariana (Araneae: Tetragnathidae). MSc thesis, Universidad de Costa Rica, San José

Méndez V, Eberhard WG, in press. Removal of genital plugs and insemination by males with normal and experimentally modified palps in Leucauge mariana (Araneae, Tetragnathidae). J Arachnol

Møller AP (1994) Sexual selection and the barn swallow. Oxford Series in Ecology and Evolution. Oxford University Press, New York

Moya-Laraño J, Cabeza M (2003) Bimodality in the body size distribution of Mediterranean tarantula juveniles: Humphreys' Russian roulette revisited. Rev Ibér Aracnol 7:211-219

Platnick NP (2013) The world spider catalog, version 13.5. 621 http:// research.amnh.org/iz/spiders/catalog/INTRO3.html

Polak M, Rashed A (2009) Microscale laser surgery reveals adaptive function of male intromittent genitalia. Proc R Soc Lond B 277: $1372-1376$

R DEVELOPMENT CORE TEAM (2013) R: a language and environment for statistical computing. R Foundation for Statistical Computing, Vienna, Austria. http://www.R-project.org/

Rubenstein DR, Hauber ME (2008) Dynamic feedback between phenotype and physiology in sexually selected traits. Trends Ecol Evol 23: 655-658

Safran RJ, Adelman JS, McGraw KJ, Hau M (2008) Sexual signal exaggeration affects physiological state in male barn swallows. Curr Biol 18:R461-R462

Uetz GW, McClintock WJ, Miller D, Smith EI, Cook KK (1996) Limb regeneration and subsequent asymmetry in a male secondary sexual character influences sexual selection in wolf spiders. Behav Ecol Sociobiol 38:253-257

Zuur AF, Ieno EN, Walker NJ, Saveliev AA, Smith GM (2009) Mixed effects models and extensions in ecology with R. Springer, New York 